\title{
ER stress preconditioning ameliorates liver damage after hemorrhagic shock and reperfusion
}

\author{
DAVID PETER OBERT ${ }^{1,2}$, ALEXANDER KARL WOLPERT ${ }^{2,3}$, NATHAN LEWIS GRIMM ${ }^{4}$ and SEBASTIAN KORFF ${ }^{2,5}$ \\ ${ }^{1}$ Department of Anesthesiology and Intensive Care, School of Medicine, Technical University of Munich, \\ 81675 Munich; ${ }^{2}$ Department of Trauma Surgery, University of Heidelberg, 69118 Heidelberg; ${ }^{3}$ Department of \\ Trauma Surgery, Paracelsus Medical University, 90471 Nuremberg, Germany; ${ }^{4}$ Department of Orthopaedic Surgery, \\ Duke University Medical Center, Durham, NC 27708, USA; ${ }^{5}$ Department of Orthopaedic Surgery, \\ Klinikum rechts der Isar, Technical University of Munich, 81675 Munich, Germany
}

Received July 2, 2020; Accepted October 28, 2020

DOI: $10.3892 / \mathrm{etm} .2021 .9679$

\begin{abstract}
The mismatch of oxygen supply and demand during hemorrhagic shock disturbs endoplasmic reticulum (ER) homeostasis. The resulting accumulation of unfolded proteins in the ER lumen, which is a condition that is defined as ER stress, triggers the unfolded protein response (UPR). Since the UPR influences the extent of organ damage following hemorrhagic shock/reperfusion (HS/R) and mediates the protective effects of stress preconditioning before ischemia-reperfusion injury, the current study investigated the mechanisms of ER stress preconditioning and its impact on post-hemorrhagic liver damage. Male C56BL/6-mice were injected intraperitoneally with the ER stress inductor tunicamycin (TM) or its drug vehicle $48 \mathrm{~h}$ prior to being subjected to a $90 \mathrm{~min}$ pressure-controlled hemorrhagic shock $(30 \pm 5 \mathrm{mmHg})$. A period of $14 \mathrm{~h}$ after hemorrhagic shock induction, mice were sacrificed. Hepatocellular damage was quantified by analyzing hepatic transaminases and hematoxylin-eosin stained liver tissue sections. Additionally, the topographic expression patterns of the ER stress marker binding immunoglobulin protein (BiP),
\end{abstract}

Correspondence to: Dr David Peter Obert, Department of Trauma Surgery, University of Heidelberg, Schlierbacher, Landstrasse 200a, 69118 Heidelberg, Germany

E-mail: david.obert@alumni.uni-heidelberg.de

Abbreviations: ALAT, alanine aminotransferase; ASAT, aspartate aminotransferase; ATF6, activating transcription factor 6; $\mathrm{BC}$, baseline control; BiP, binding immunoglobulin protein; DV, drug vehicle; ER, endoplasmic reticulum; H\&E, hematoxylin and eosin; HS/R, hemorrhagic shock and reperfusion; HSP, heat-shock protein; IRE1, inositol-requiring enzyme 1; IRI, ischemia-reperfusion injury; Nrf2, nuclear factor erythroid 2-related factor 2; $\mathrm{PH}$, partial hepatectomy; SC, sham control; sXBP1, spliced version of XBP1; TM, tunicamycin; TUDCA, tauroursodeoxycholic acid; UPR, unfolded protein response; XBP1, X-box binding protein 1

Key words: hemorrhage, unfolded protein response, tunicamycin, ischemia-reperfusion injury, binding immunoglobulin protein
UPR signaling pathways, and the autophagy marker Beclin1 were evaluated. TM injection significantly increased BiP expression and modified the topographic expression patterns of the UPR signaling proteins. In addition, immunohistochemical analysis of Beclin1 revealed an increased pericentral staining intensity following TM pretreatment. The histologic analysis of hepatocellular damage demonstrated a significant reduction in cell death areas in $\mathrm{HS} / \mathrm{R}+\mathrm{TM}(\mathrm{P}=0.024)$. ER stress preconditioning influences the UPR and alleviates post-hemorrhagic liver damage. The beneficial effects were, at least partially, mediated by the upregulation of $\mathrm{BiP}$ and autophagy induction. These results underscore the importance of the UPR in the context of HS/R and may help identify novel therapeutic targets.

\section{Introduction}

Trauma is the most common cause of death for all age groups below the age of 44 and the single largest cause for years of life lost in the United States (1-3). Acute trauma care, therefore, is not only of the utmost importance from a clinical point of view but also from a public health perspective (4). One of the most dire consequences of severe trauma, and a leading cause of post-injury death, is hemorrhagic shock as it may result in ischemia-reperfusion injury (IRI), systemic inflammation, and multi-organ failure (5). Despite enormous amounts of research, the underlying pathomechanisms are still poorly understood, hindering a target-oriented therapy.

Hemorrhagic shock is known to cause a mismatch between oxygen supply and demand. The tissue hypoxia that occurs results in pathophysiological disturbances of the cellular machinery. Protein maturation and folding in the endoplasmic reticulum (ER) is a highly energy-dependent cellular process (6). Perturbations in the ER homeostasis result in an impaired ER function and an accumulation of unfolded proteins in the ER lumen-a condition defined as ER stress (7). Consequently, the cell activates specific signaling pathways, which are collectively known as the unfolded protein response (UPR) consisting of three primary branches: Protein kinase RNA-like endoplasmic reticulum kinase (PERK), activating transcription factor 6 (ATF6), and inositol-requiring enzyme 1 
(IRE1). Under physiological conditions, binding immunoglobulin protein $(\mathrm{BiP})$, a molecular chaperone and master regulator of ER function, binds to the luminal domains of PERK, ATF6, and IRE1 (8). Upon ER stress, BiP dissociates from each stress sensor and facilitates their activation. Whereas PERK and IRE1 undergo oligomerization and trans-autophosphorylation (9), ATF6 is activated by proteolytic cleavage in the Golgi compartment (10). After its translocation to the nucleus, ATF6 promotes the transcription of genes coding for adaptive proteins, such as chaperones, and of X-box binding protein 1 (XBP1) mRNA (11). Before its translation, XBP1 mRNA is spliced by activated IRE1 endoribonuclease (12). XBP1 codes for an active transcription factor, which amplifies the synthesis of components of the ER-associated protein degradation machinery (13). Additionally, the activation of the PERK pathway results in a global attenuation of protein synthesis by phosphorylation of eukaryotic initiation factor $2 \alpha(\mathrm{IFF} 2 \alpha)$ (14). In brief, the UPR is primarily a pro-survival cellular response aiming to restore protein homeostasis in the ER by facilitating protein folding, reducing protein synthesis, and increasing protein degradation. However, if the UPR fails to reestablish protein homeostasis and ER stress persists, cell death may occur (15).

As reported in previous studies, the above-described cellular mechanisms influence the extent of liver damage following hemorrhagic shock and reperfusion (HS/R) (16-18). Furthermore, the UPR mediates the protective effects of stress preconditioning, an established concept to mitigate subsequent IRI. Previous studies have demonstrated that ischemia-reperfusion associated hepatocellular, myocardial, and neuronal cell damage can be alleviated by stress preconditioning (e.g. by remote ischemic preconditioning or lipopolysaccharide pretreatment) $(19,20)$. From a clinical point of view, the therapeutic potential of this method has already been demonstrated by the bench-to-bedside transfer of remote ischemic preconditioning in patients undergoing coronary artery bypass surgery $(21,22)$. Even though IRI and HS/R signaling pathways have been studied for decades, some of the underlying mechanisms remain elusive. However, developing novel therapeutic approaches requires a deeper understanding of the pathophysiology of IRI and HS/R. Based on the above-described findings and our previous results, we hypothesized that ER stress preconditioning alleviates liver damage following $\mathrm{HS} / \mathrm{R}$ and may thereby reveal a target with potential therapeutic relevance. To investigate this hypothesis and to identify the underlying protective mechanisms, we injected mice with the pharmacological ER stress inducer tunicamycin (TM) and subjected them to HS/R $48 \mathrm{~h}$ later.

\section{Materials and methods}

Animal care. C57BL/6 mice, 10 weeks of age, were purchased from Charles River Laboratories (Sulzfeld, Germany). Due to the influence of female sex steroids on post-hemorrhagic organ damage, only male mice were included (23). The animals were housed in the animal facility of the University of Heidelberg at a temperature of $21^{\circ} \mathrm{C}$ and a $12 \mathrm{~h} \mathrm{light/dark} \mathrm{cycle.} \mathrm{The} \mathrm{mice}$ had one to two weeks for acclimatization and had access to water and chow ad libitum. During acclimatization the animals were housed in group cages and with start of the experiment animals were placed individually. All study protocols were reviewed and approved by the section for agriculture and veterinary services of the Regional Council, Karlsruhe, Germany (35-9185.81/G-65/13).

Experimental model. The shock protocol was performed as previously published $(17,18)$. Briefly, anesthesia was induced via inhalation of $4 \%$ isoflurane (Abbott Laboratories Ltd.) in an acrylic glass chamber. After loss of righting reflex the animals were placed in a supine position on a heating cushion and anesthesia was maintained by administering $\sim 1.2 \%$ isoflurane via a face mask. For temperature control $\left(37.0 \pm 0.5^{\circ} \mathrm{C}\right)$ a rectal probe was inserted. Before the bilateral dissection of the groins, $25 \mu \mathrm{l}(\sim 5 \mathrm{mg} / \mathrm{kg}$ body weight) of $0.5 \%$ Bupivacaine hydrochloride (AstraZeneca Gmbh) was applied for local anesthesia intraincisionally. Subsequently, the femoral arteries were cannulated with a polyethylene tubing, previously flushed with a heparin solution. The right catheter was connected to a blood pressure analyzer (BPA-400, Micro-med Inc.), the left catheter was used to withdraw blood and induce a hemorrhagic shock. The mean arterial pressure (MAP) was maintained for $90 \mathrm{~min}$ at $30 \pm 5 \mathrm{mmHg}$. Afterwards, Ringer's solution, three times the shed blood volume, was injected for resuscitation. Subsequently, the catheters were removed, the vessels were ligated, and the skin was closed. After the discontinuation of isoflurane inhalation, the mouse was placed in its cage and observed till emergence.

Mice were randomly assigned to five different groups. $\mathrm{HS} / \mathrm{R}$ groups were treated as outlined above. Depending on the group assignment mice received either TM $(0.75 \mathrm{mg} / \mathrm{kg}$ BW in solution, Merck KGaA) or its drug vehicle (DV) dimethyl sulfoxide (DMSO), dissolved in $100 \mu$ l Ringer's solution, which was given intraperitoneally $48 \mathrm{~h}$ before shock induction. Sham controls (SC) were created for each HS/R group. SC groups received the same treatment as the corresponding HS/R group but did not undergo hemorrhagic shock. For the evaluation of physiologic baseline values, euthanasia was performed under anesthesia without any prior treatment given to the mice. This baseline control (BC) group as well as the HS/R+TM group consisted of six animals whereas all other groups ( $\mathrm{SC}+\mathrm{DV}, \mathrm{SC}+\mathrm{TM}$, $\mathrm{HS} / \mathrm{R}+\mathrm{DV}$ ) contained three animals. Experimental group size calculation was based on our previous study, which compared mice undergoing $\mathrm{HS} / \mathrm{R}$ procedure and receiving the drug vehicle (DV) DMSO during reperfusion with mice undergoing $\mathrm{HS} / \mathrm{R}$ procedure without any pharmaceutical intervention (18). Each group included 6-7 animals. The same comparison was performed for mice undergoing sham procedure with 5 animals per group. Using Mann-Whitney $\mathrm{U}$ test we could not find any significant differences in transaminase levels or percentage of cell death areas (HS/R groups). Therefore, we concluded that the applied dosage of our solvent DMSO does not influence our main outcome parameters and decided to limit the number to three animals per control group in the present study.

Tissue harvesting and plasma analysis. A period of $14 \mathrm{~h}$ after shock induction, anesthesia was induced and maintained via 
inhalation of $4 \%$ isoflurane. After loss of the paw withdrawal reflex and observation of agonal breathing, a laparotomy and thoracotomy were performed. For euthanasia the right heart ventricle was punctured using a heparinized 1-ml syringe. Death was confirmed by observation of cardiac and respiratory arrest. The collected blood was centrifuged (10 and $5 \mathrm{~min}$ at $2,000 \mathrm{x} \mathrm{g}$ ) and $50 \mu \mathrm{l}$ of the plasma was used to measure aspartate aminotransferase (ASAT) as well as alanine aminotransferase (ALAT) concentrations (Fuji Dri-Chem NX500i; FujiFilm Europe GmbH). Subsequently, the body was flushed with a heparin solution through puncture of the left ventricle. The liver was then harvested and halved. One half was snap-frozen by submerging the sample tubes into liquid nitrogen and the other half was placed in $4 \%$ paraformaldehyde (PFA).

Histology. After fixation in 4\% PFA for at least $24 \mathrm{~h}$ the livers were dehydrated using a series of alcohols with increasing concentrations and acetone. Hereafter, the organs were embedded in paraffin. The tissues were then cut into $5 \mu \mathrm{m}$ sections. For deparaffinization the slides were placed in xylene and afterwards immersed in a series of alcohols with decreasing concentrations for rehydration. The sections were then either processed for immunohistochemistry or stained with hematoxylin and eosin (H\&E) using a standard protocol. To quantify liver damage, the H\&E-stained liver tissue sections were assessed for dead cells assessed by at least two investigators experienced in analyzing histological slides. We first measured the percentage of vessels and dead cells using ImageJ (Version: 1.51f; Wayne Rasband, National Institutes of Health). In the following, the number of pixels covered by vessels were subtracted from the total pixel amount and the percentage of irreversibly damaged tissue was calculated. Corresponding morphological features were a rupture of the nuclear envelope or chromatin condensation, loss of cell borders with irregular fragmentation and/or washed-out image of cytoplasm $(24,25)$. Since cell swelling per se is a reversible state, swollen cells were not considered as dead cells (24). Six-eight representative visual fields (100 x) per animal of the HS/R+DV and 1-5 representative visual fields per animal of the HS/R+TM group were analyzed. In total, we evaluated 20 representative visual fields for each HS/R group. The varying numbers of analyzed visual fields per animal resulted from the different group sizes. Subsequently, the median percentage of damaged tissue per animal was calculated and used for further statistical analysis.

Immunohistochemistry. Immunohistochemical staining was performed as previously published $(17,18)$. In the following, we describe the BiP staining more detailed since that was our standard protocol. Therefore, only the differences to the BiP staining process are mentioned for the other staining procedures.

$B i P$. After deparaffinization and rehydration the tissue sections were immersed in $0.45 \%$ hydrogen peroxide for $20 \mathrm{~min}$ to block the endogenous peroxidase activity. Heat-induced antigen retrieval was performed by placing the sections for $20 \mathrm{~min}$ in a citrate buffer $(\mathrm{pH} 6.0,10 \mathrm{mM})$ set to $100^{\circ} \mathrm{C}$. Following this, the blocking agent, $1.5 \%$ donkey serum (\#sc-2023, Santa Cruz Biotechnology, Inc.) in phosphate buffered saline (PBS), was applied. The tissue sections were then incubated overnight at $4^{\circ} \mathrm{C}$ with the primary antibody, goat anti-BiP (\#sc-1050, Santa Cruz Biotechnology, Inc.), at a dilution of 1:50. In the next step, the secondary antibody, donkey anti-goat IgG (\#sc-2023, Santa Cruz Biotechnology, Inc.), was administered for $30 \mathrm{~min}$ at room temperature, diluted at 1:200. For signal detection, alkaline phosphatase (AP; \#AK-5000, Vector Laboratories) was applied and Fast Red was used as chromogen. To stop the reaction, the slides were immersed in distilled water. Finally, hematoxylin was applied for counterstaining and the slides were mounted using an aqueous mountant.

ATF6. 2.5\% horse serum was used as a blocking solution (\#MP-5401, Vector Laboratories, Inc.). The tissue sections were incubated overnight at $4^{\circ} \mathrm{C}$ with the rabbit anti-ATF6 antibody (\#NBP1-77251, Novus Biologicals Europe, Cambridge, Great Britain), diluted at 1:100. As secondary antibody we applied a horse anti-rabbit antibody for $30 \mathrm{~min}$ at room temperature, which was supplied as ready-to-use kit and already conjugated with alkaline phosphatase by the manufacturer (\#MP-5401, Vector Laboratories, Inc.).

$p P E R K$. To block unspecific antibody binding sites, a solution of 5\% skim milk and 1\% BSA was applied. Afterwards, the primary antibody, rabbit anti-pPERK (\#ab192591, Abcam plc.,), incubated overnight at $4^{\circ} \mathrm{C}$ at a 1:50 dilution. The slides were then covered with the secondary antibody for $30 \mathrm{~min}$ at room temperature, a ready-to-use alkaline phosphatase polymer anti-rabbit reagent (\#MP-5401, Vector Laboratories, Inc.).

$s X B P 1$. After the blocking procedure with $1.5 \%$ donkey serum (\#sc-2023, Santa Cruz Biotechnology, Inc.), the slides were incubated overnight at $4^{\circ} \mathrm{C}$ with the goat anti-XBP1 antibody (\#ab85546, Abcam plc.), diluted at 1:100. Subsequently, the secondary antibody (\#sc-2023; Santa Cruz Biotechnology, Inc.), diluted at 1:200 in 1.5\% donkey serum, was applied for $30 \mathrm{~min}$ at room temperature.

Beclin 1. For deparaffinization the slides were placed in xylene before being rehydrated by immersion in $100 \%$ isopropanol. Afterwards, the endogenous peroxidase activity was blocked by $1.5 \%$ methanol and antigen retrieval was performed as described above. To block unspecific binding sites $2.5 \%$ horse serum was applied. Next, the slides were incubated for one hour at room temperature with the primary antibody, rabbit anti-Beclin1 IgG (\#NB500-249, Novus Biologicals Europe), at a dilution of 1:400 before the secondary antibody (\#MP-5401, Vector Laboratories, Inc.) was applied for $30 \mathrm{~min}$ at room temperature.

Western blot analysis. The frozen livers were thawed and homogenized using a homogenization buffer $(5 \mathrm{mmol} / 1$ 3-(N-morpholino) propanesulfonic acid, $1 \mathrm{mmol} / 1$ ethylenediaminetetraacetic acid, $0.25 \mathrm{~mol} / 1$ sucrose, $0.2 \mathrm{mmol} / \mathrm{l}$ dithiothreitol, $1 \mathrm{mmol} / 1 \mathrm{\varepsilon}$-aminocaproic acid, $5 \mathrm{mmol} / 1$ benzamidine, $0.2 \mathrm{mmol} / \mathrm{l}$ phenylmethylsulfonyl fluoride, $0.1 \%$ Triton $\mathrm{X}-100)$. After centrifugation at $15.400 \mathrm{~g}$ for $15 \mathrm{~min}$ at $4^{\circ} \mathrm{C}$ the 

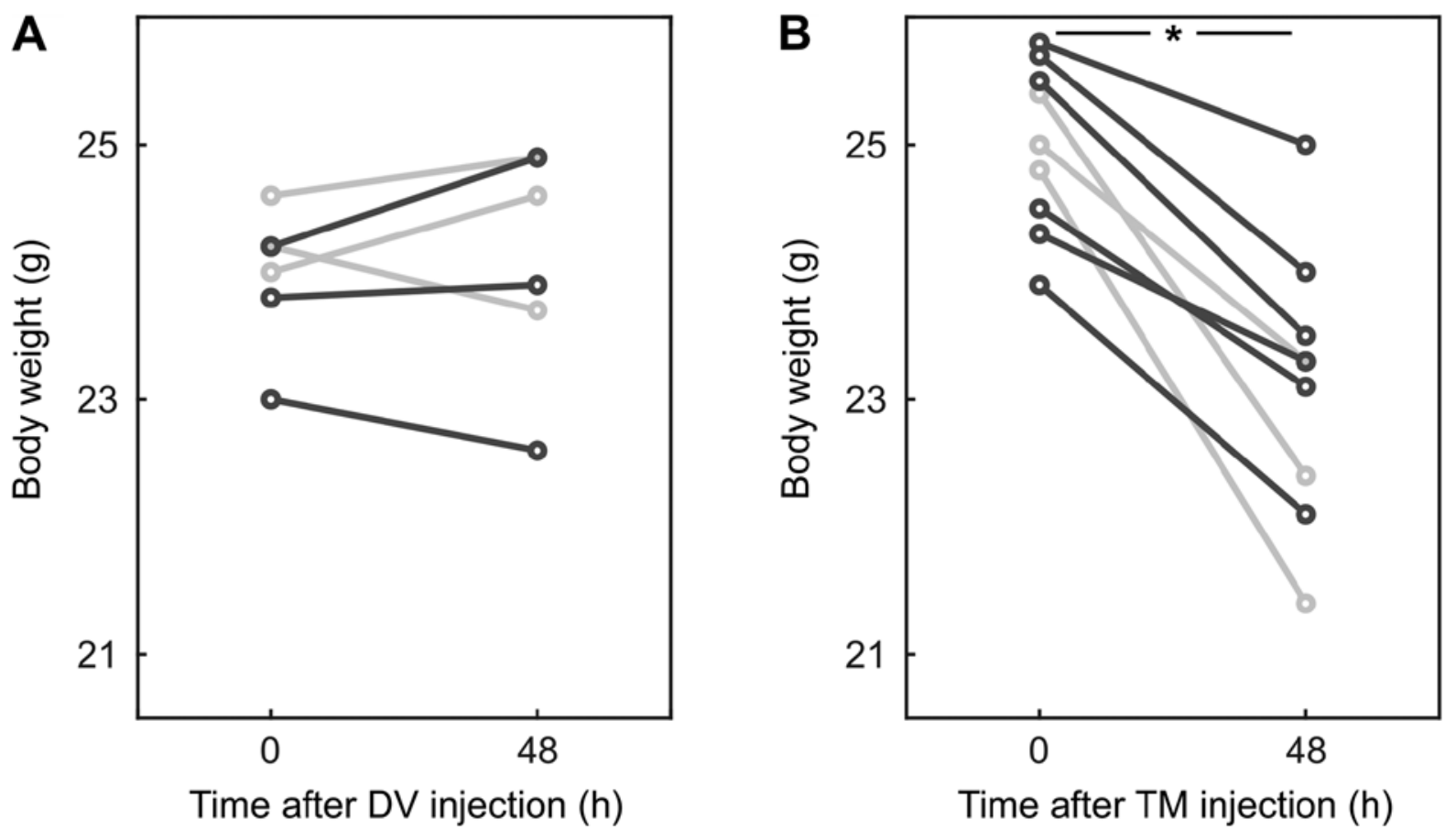

Figure 1. TM injection was followed by body weight loss. Display of body weight in gram $(\mathrm{g})$ at the time of the injection and before the beginning of the surgical procedure, $48 \mathrm{~h}$ later. The light gray lines represent animals of the sham control and the dark gray lines animals of the hemorrhagic shock and reperfusion group. (A) The body weight of mice ( $\mathrm{n}=6)$ receiving the DV at 0 and $48 \mathrm{~h}$. (B) Mice treated with TM injection mice at 0 and $48 \mathrm{~h}$. "P<0.01 ( $\mathrm{n}=9$ ). TM, tunicamycin; DV, drug vehicle.

protein samples were fractionated by electrophoresis on sodium dodecyl sulfate polyacrylamide gel. Subsequently, the separated proteins were transferred to a polyvinylidene fluoride membrane (\#1620177, Bio-Rad Laboratories $\mathrm{GmbH})$. The membranes were then washed with PBS-Tween $(0.05 \%)$ followed by the saturation with $5 \%$ skim milk in PBS-Tween for one hour at room temperature to block non-specific binding sites. Afterwards, the membranes were incubated overnight at $4^{\circ} \mathrm{C}$ with the primary antibody, goat anti-BiP (\#sc-1050, Santa Cruz Biotechnology, Inc.), diluted at 1:500 in 5\% skim milk. Before and after the incubation for one hour at room temperature with the HRP-conjugated secondary antibody, donkey anti-goat IgG (\#sc-2020, Santa Cruz Biotechnology, Inc.) diluted at 1:5,000 in 5\% skim milk, the membranes were washed with PBS-Tween. Enhanced chemiluminescent substrate was added and the signal was detected using Image Reader LAS-3000 Version 2.0 (Fuji Photo Film). For loading control, the membranes were incubated for two hours at room temperature with rabbit anti-glyceraldehyde 3-phosphate dehydrogenase (GAPDH) antibody (\#sc-25778, Santa Cruz Biotechnology, Inc.) diluted at 1:500 in 1\% newborn calf serum.

Regarding the quantification of BiP expression, we loaded two reference samples on each plot to allow a comparison of different plots. For the analysis we used the ImageJ (Version: 1.51f; Wayne Rasband, National Institutes of Health). We selected the lanes, plotted them and labelled the peaks. After converting the number of pixels of each lane into percentage we divided the percentage of each sample by the percentage of our reference sample. These steps were performed for BiP as well as for GAPDH. We finally divided the calculated values and received the ratio of BiP to GAPDH expression. Using this approach, the analysis was adjusted to inconsistent GAPDH expressions.

Statistical analyses. Statistical analysis was performed using MATLAB R2018b (The MathWorks Inc.). Shapiro-Wilk test showed a non-parametric distribution of the data. Therefore, the Kruskal-Wallis test was used for the comparison of more than two groups, together with Tukey-Kramer post-hoc correction. For the comparison of two groups the Wilcoxon Mann-Whitney test was applied. Data are expressed as median [minimum; maximum]. A p-value below 0.05 was considered statistically significant. We additionally present the Area Under the Curve (AUC) with bootstrapped 95\% confidence intervals as effect size. For this we used the MATLAB-based MES toolbox (26). The use of AUC helps to evaluate the strength of an effect (27).

\section{Results}

Model evaluation. Fixed pressure-controlled hemorrhagic shock was shown to be a reliable and reproducible model (28). The mice used in this experiment did not differ in age, body weight, or strain from previous studies $(17,18)$. As four animals had to be excluded, e.g. due to death during hemorrhagic shock $(n=1)$, malformations $(n=1)$, or inconsistent shock with more than three peaks above $35 \mathrm{mmHg}(\mathrm{n}=2)$, we included 21 animals in our analysis. The mean blood volume to induce and maintain a mean arterial pressure of $30 \pm 5 \mathrm{mmHg}$ for 90 min was $0.60[0.50 ; 0.65] \mathrm{ml}(2.45[2.10 ; 2.94] \mathrm{ml}$ per $100 \mathrm{~g}$ body weight) and did not differ significantly between the shock groups. Furthermore, there were no significant differences 

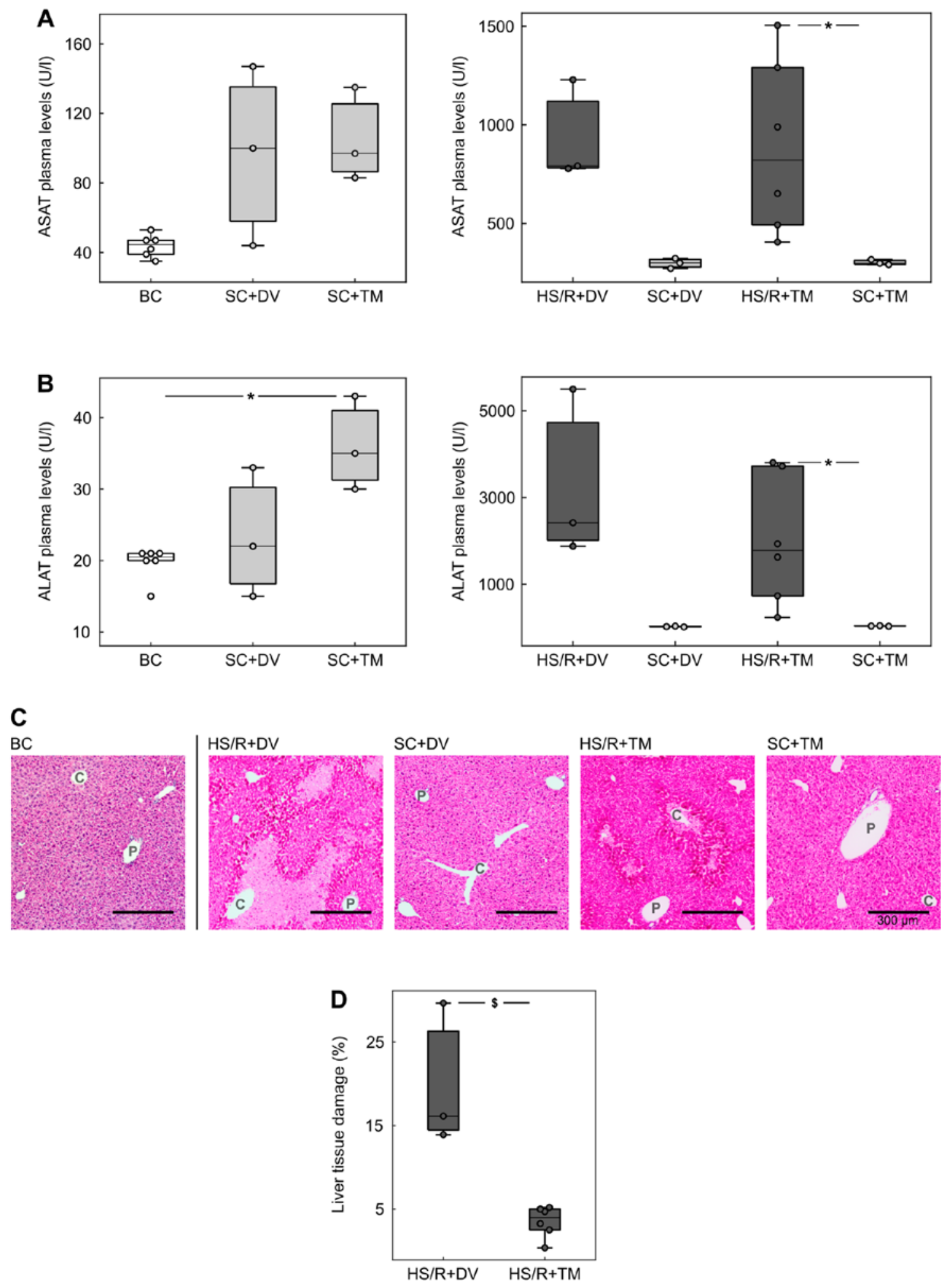

Figure 2. TM preconditioning mitigated liver damage after HS/R. (A) ASAT and (B) ALAT plasma levels in Units per liter (U/l). (C) Representative hematoxylin and eosin stains of liver tissue sections. Scale bar, $300 \mu \mathrm{m}$. (D) The quantification of cell death areas after HS/R was performed by analyzing 6-8 representative visual fields (magnification, $x 100)$ per animal of the HS/R+DV ( $\mathrm{n}=3$ ) and 1-5 representative visual fields per animal of the HS/R+TM group $(\mathrm{n}=6)$. One circle displays the median percentage of damaged tissue of one animal. ${ }^{*} \mathrm{P}<0.05 ;{ }^{\$} \mathrm{P}<0.01$. HS/R, hemorrhagic shock and reperfusion; ASAT, Aspartate aminotransferase; ALAT, alanine aminotransferase; DV, drug vehicle; TM, tunicamycin.

between the groups regarding the body weight at the start of the experiment. However, mice which received TM lost 6.8 $[3.1 ; 13.7] \%$ of their body weight within $48 \mathrm{~h}(\mathrm{P}=0.004$; AUC 0.93 [0.78 1]; Fig. 1).
TM preconditioning alleviated liver damage. To assess the extent of liver damage, plasma concentrations of ASAT and ALAT were measured as their plasma levels correlate with hepatocellular injury (29) (Fig. 2A and B). The comparison of 
A BC
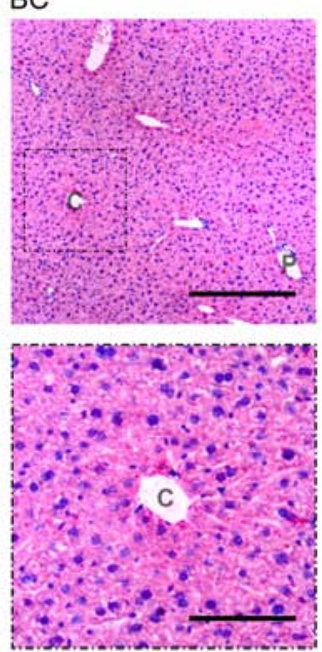

$H S / R+D V$
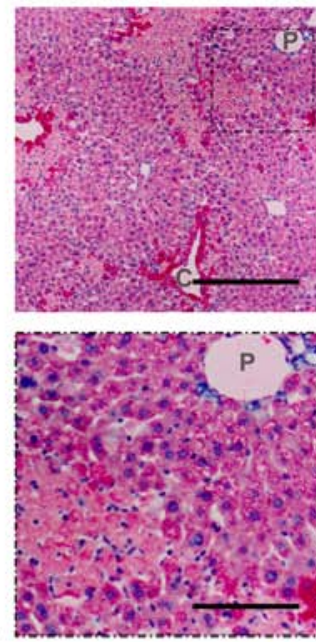

$\mathrm{SC}+\mathrm{DV}$
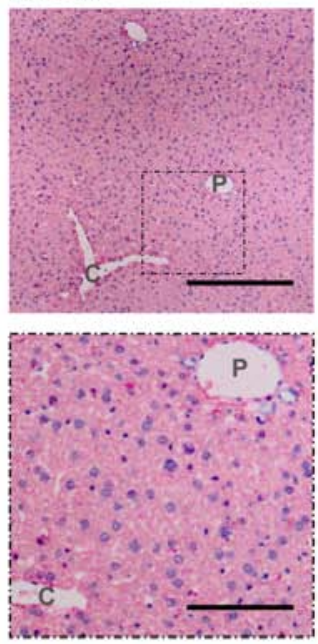

$\mathrm{HS} / \mathrm{R}+\mathrm{TM}$
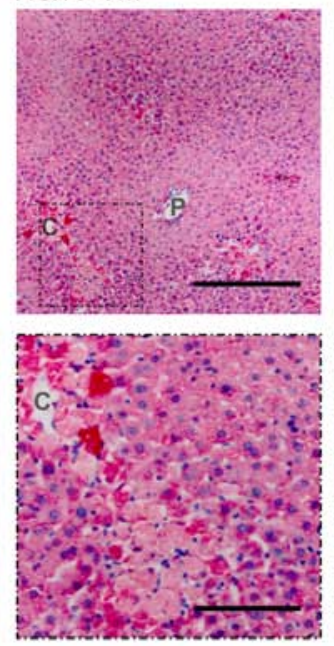

$\mathrm{SC}+\mathrm{TM}$
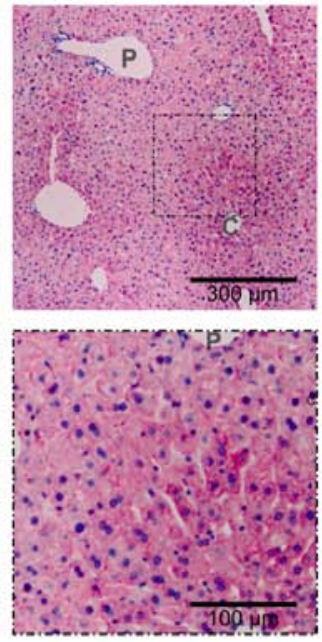
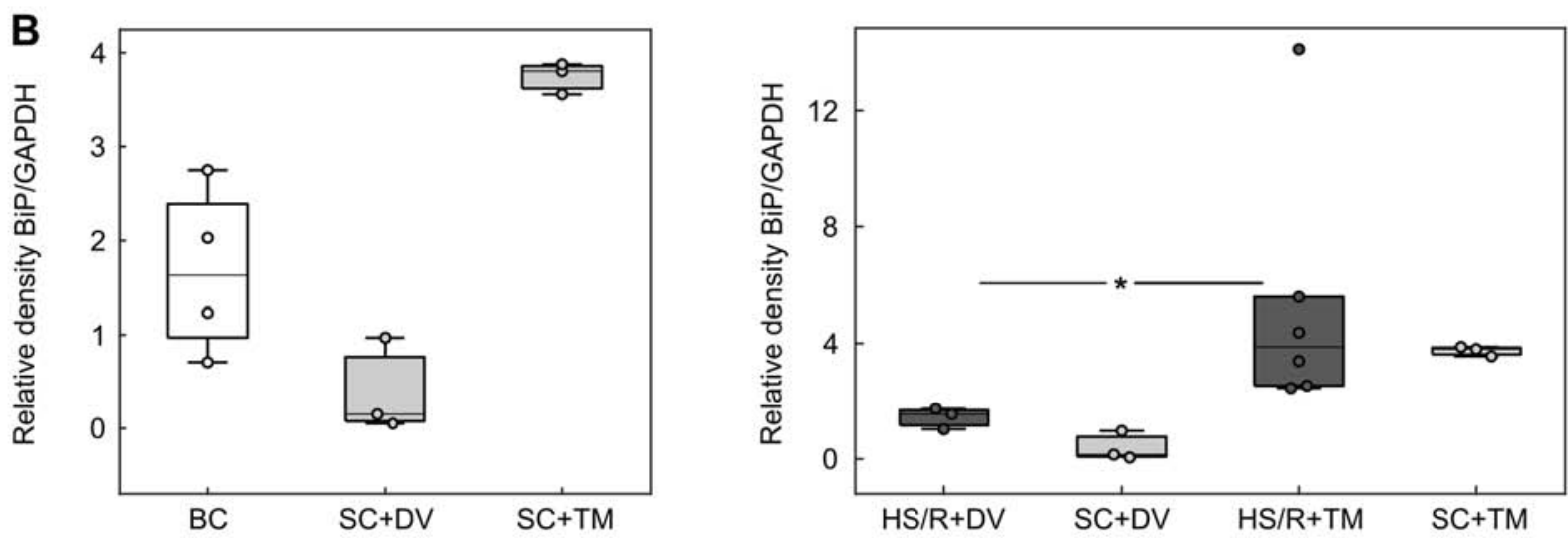

C
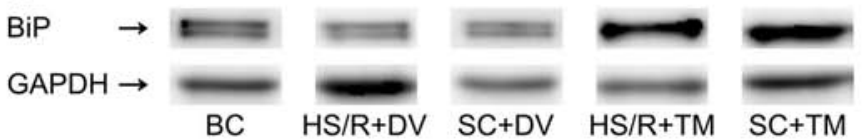

Figure 3. TM preconditioning induces BiP expression. (A) Representative immunostainings of the endoplasmic reticulum stress marker BiP. Scale bar of upper row, $300 \mu \mathrm{m}$; Scale bar of lower row, $100 \mu \mathrm{m}$. Vessels of the periportal field (P) and central veins (C) are exemplified. (B) Protein expression was quantified by calculating the relative density of BiP to GAPDH. SCs and HS/R+DV included three animals, BC and $\mathrm{HS} / \mathrm{R}+\mathrm{TM}$ consisted of six mice. ${ }^{*} \mathrm{P}<0.05$. BiP, binding immunoglobulin protein; SC, sham control; HS/R, hemorrhagic shock and reperfusion; DV, drug vehicle; TM, tunicamycin; BC, baseline control.

the control groups (BC, SC+DV, SC+TM) showed no significant differences except for the ALAT concentration in SC+TM group $(35.0[30.0 ; 43.0] \mathrm{U} / \mathrm{l})$, which was significantly higher than in BC (20.5 [15.0; 21.0] U/1, P=0.047; AUC 0 [0 0]). The ASAT/ALAT levels in the shock groups were similar: 1141.5 [312.0; 2510.0] U/1 and 1778.0 [235.0; 3805.0] U/1 in HS/R+TM group vs. 1084.0 [1058.0; 1958.0] U/l and 2417 [1876.0; 5499.0] $\mathrm{U} / 1$ in the HS/R+DV group. The comparison of the shock groups with their corresponding sham groups demonstrated more than 10-fold higher transaminases concentrations in the HS/R groups. This difference was significant for TM groups $(\mathrm{P}=0.024$; AUC $0[0$ 0]) and non-significant for the DV groups $(\mathrm{P}=0.1)$.

Additionally, H\&E-staining of liver tissue sections was performed to confirm the results of the plasma measurements (Fig. 2C and D). The evaluation of baseline and sham controls showed no obvious signs of hepatocellular damage. In contrast to this finding, there were cell death areas spreading centrifugally from the central vein in both shock groups. The quantification of these areas revealed that the percentage of damaged liver tissue was significantly lower in the HS/R+TM group $(4.0[0.4 ; 13.9] \%)$ compared to the HS/R+DV group (16.1 $[5.2 ; 30.0] \% ; \mathrm{P}=0.024)$. This finding is underlined by an AUC of $0[00]$.

BiP expression was upregulated by TM preconditioning. To investigate the influence of TM preconditioning on the ER, we analyzed the expression of $\mathrm{BiP}$, a master regulator of ER function and a known ER stress marker $(8,30)$. Immunohistochemistry displayed a homogeneous staining of the liver sections in $\mathrm{BC}$ and $\mathrm{SC}+\mathrm{DV}$ groups (Fig. 3A). In the HS/R+DV group the vital parenchyma was also homogenously stained but the staining intensity appeared to be higher compared to its corresponding sham group. Furthermore, 

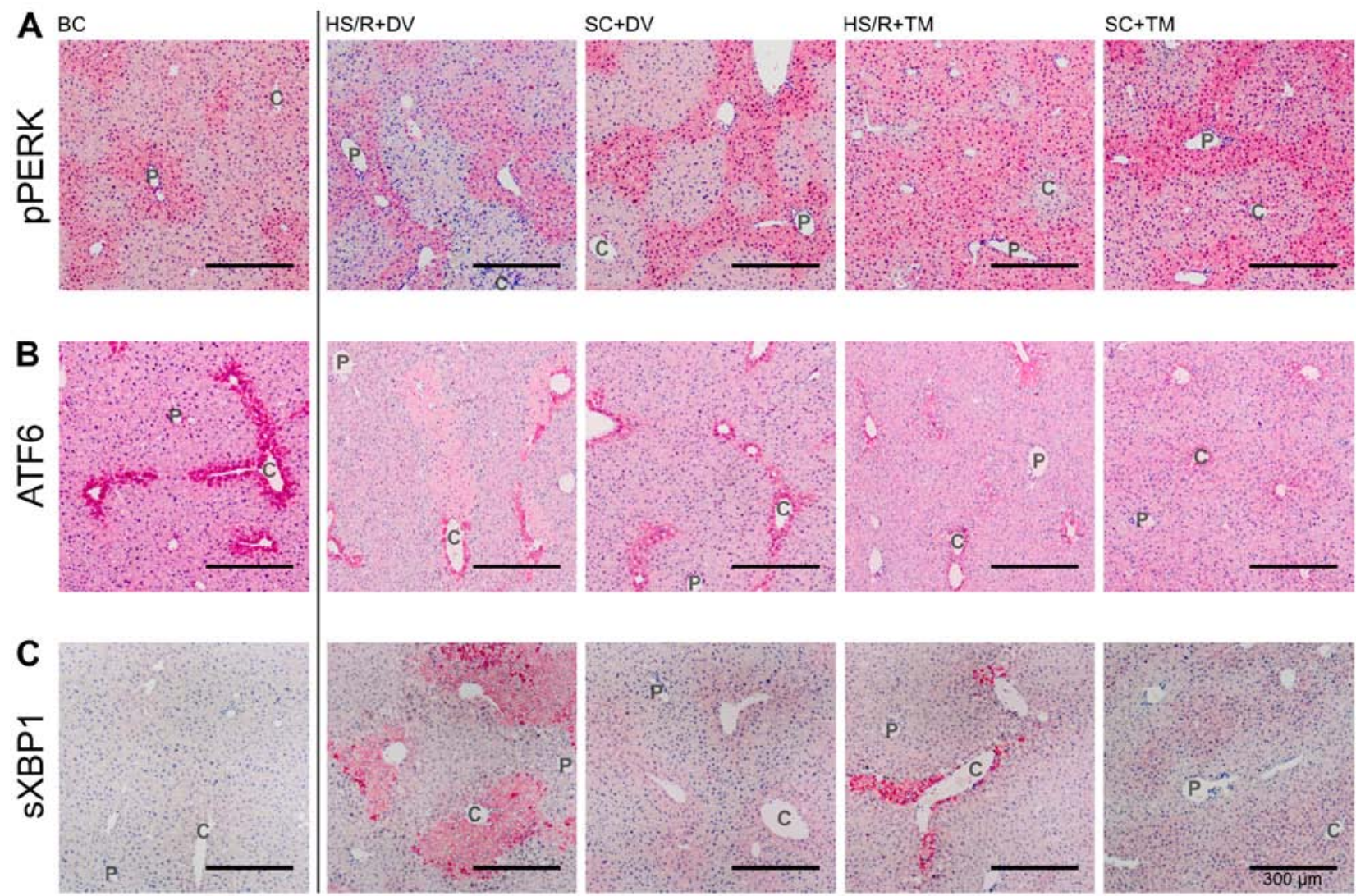

Figure 4. Topographical changes of UPR signaling. Representative stains of the immunohistochemical proof of pPERK, ATF6, and sXBP1. Vessels of the periportal field (P) and central veins (C) are exemplified. Immunohistochemical staining for detection of (A) pPERK, (B) ATF6 and (C) sXBP1 in the different groups. Scale bar, $300 \mu \mathrm{m}$. pPERK, phosphorylated protein kinase RNA-like endoplasmic reticulum kinase; ATF6, activating transcription factor 6; sXBP1, spliced Version of X-box binding protein 1; SC, sham control; HS/R, hemorrhagic shock and reperfusion; DV, drug vehicle; TM, tunicamycin; BC, baseline control; UPR, unfolded protein response.

there were single, intensely stained cells adjacent to the cell death areas. These cells were also seen in the HS/R+TM group. However, the BiP baseline expression pattern in $\mathrm{HS} / \mathrm{R}+\mathrm{TM}$ and SC+TM varied from all other groups. Liver tissue sections of mice, which received TM, displayed an increasing gradient of $\mathrm{BiP}$ expression from the periportal field to the central vein.

For the evaluation of BiP expression in whole liver homogenates western blotting was performed (Fig. 3B and 3C). The analysis demonstrated an increased $\mathrm{BiP}$ expression in both TM groups. Compared to the HS/R+DV (1.55 [1.03; 1.74]), the HS/R+TM group $(3.88$ [2.46; 14.11]) showed a significantly higher $\mathrm{BiP} / \mathrm{GAPDH}$ ratio depicted by $\mathrm{P}=0.024$ and an $\mathrm{AUC}$ of 1 [1 1 1].

Topographical changes in the UPR after TM preconditioning. Since PERK undergoes autophosphorylation upon ER stress, phosphorylated PERK (pPERK) indicates its activation (9). The pPERK staining was predominated by an increased staining intensity around the periportal field (Fig. 4A). This pattern was observed in the BC, SC+DV, SC+TM, and HS/R+DV group. However, the difference in the periportal and pericentral staining intensity appeared to be smaller in the SC+TM group compared to the $\mathrm{SC}+\mathrm{DV}$ group. Liver tissue sections of HS/R+TM group showed a similar pericentral as well as periportal expression level displayed by a homogeneous, intense staining.
ATF6 is constitutively expressed (31). Upon ER stress, its activation is initiated by the dissociation from BiP, followed by proteolytic cleavage in the Golgi compartment (32). The ATF6 expression pattern was characterized by a homogeneous staining of the vital liver parenchyma and one row of intensely stained cells around the central vein (Fig. 4B). In the SC+TM group the pericentral cells were not as intensely stained as in the other groups. In this group, a smooth transition from the intensely stained pericentral area to the remaining liver parenchyma was detected.

Since activated IRE1 splices XBP1 mRNA, measuring spliced XBP1 (sXBP1) is a reliable, indirect method of assessing IRE1 activation (30). In the BC group only a slight, homogeneous expression could be detected (Fig. 4C). The staining pattern in SC+DV was characterized by an increased pericentral intensity that faded out centrifugally. Whereas in HS/R+DV a sharp transition between intensely stained cell death areas and slightly stained vital parenchyma was found the staining pattern in $\mathrm{SC}+\mathrm{TM}$ and $\mathrm{HS} / \mathrm{R}+\mathrm{TM}$ was similar to SC+DV.

TM preconditioning induced pericentral autophagy. Beclin1 is a known marker of autophagy, which is naturally expressed in biliary epithelium (33). In the BC, SC+DV, and HS/R+DV group Beclin1 was scarcely expressed indicated by a weak and partly missing staining of the vital parenchyma (Fig. 5). In contrast to this finding, both TM groups showed an increased 

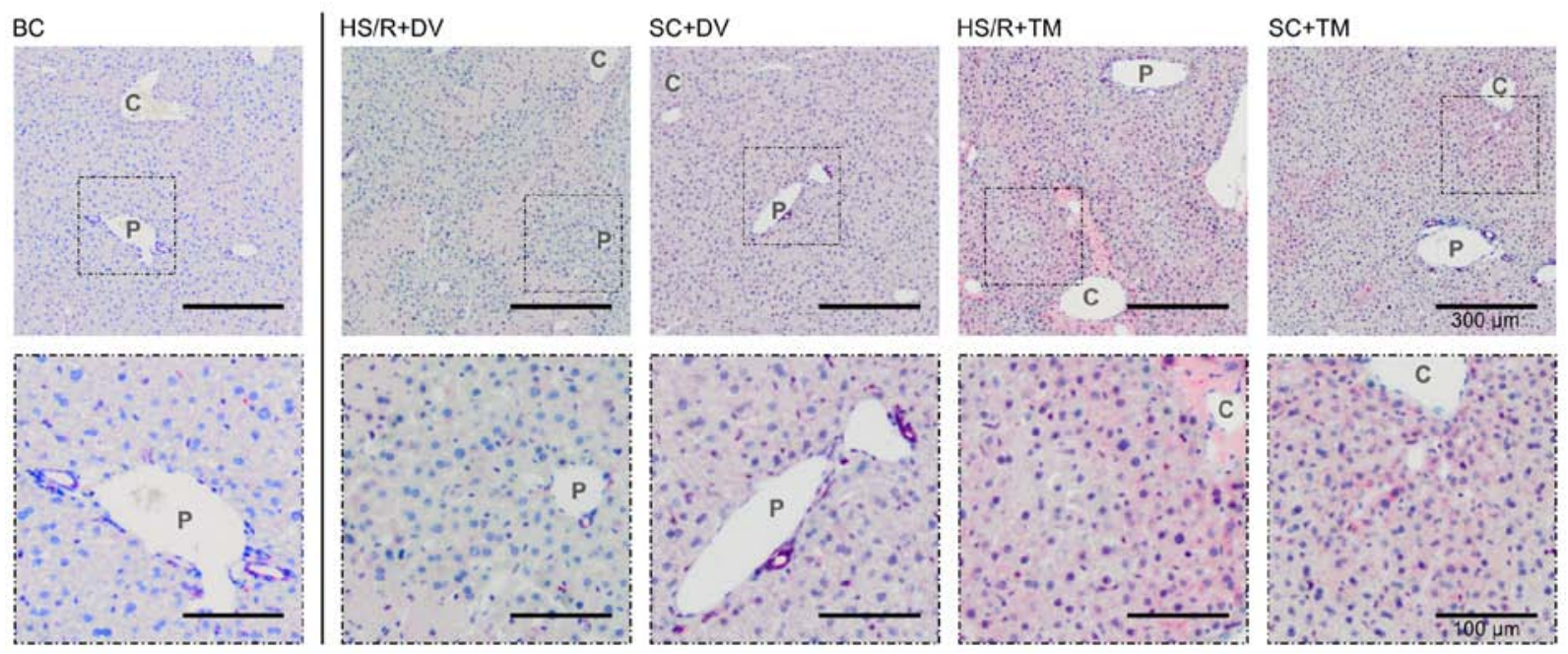

Figure 5. Pericentral Beclin1 upregulation by TM preconditioning. Immunohistochemical stained liver tissue sections for the autophagy marker Beclin1. Vessels of the periportal field (P) and central veins (C) are exemplified. Scale bar of upper row, $300 \mu \mathrm{m}$; Scale bar of lower row, $100 \mu \mathrm{m}$. SC, sham control; HS/R, hemorrhagic shock and reperfusion; DV, drug vehicle; TM, tunicamycin; BC, baseline control.

Beclin1 expression pericentrally. Similar to the BiP staining pattern an increasing staining intensity from the periportal field to the central vein was observed.

\section{Discussion}

As previously shown by Jian et al (16), ER stress plays an important role in liver injury following HS/R. We confirmed this finding in our preceding study: The injection of the ER stress inhibitor tauroursodeoxycholic acid (TUDCA) during reperfusion mitigated hepatocellular damage, whereas the administration of the ER stress inductor TM during reperfusion increased hepatocellular damage (18). In addition, we conducted a detailed timeline investigation of the temporal dynamics of the expression of UPR signaling proteins and liver injury (17). Our analysis revealed a maximum of hepatocellular damage $14 \mathrm{~h}$ after shock induction. Since the focus of the present study was on liver damage, we chose to sacrifice mice $14 \mathrm{~h}$ after hemorrhagic shock induction.

TM is a pharmaceutical ER stress inducer and acts via an inhibition of $\mathrm{N}$-glycosylation, causing an accumulation of unfolded glycoproteins in the ER $(30,34)$. In accordance with previous studies, the results of the western blot analysis of whole-organ homogenates demonstrated an increased BiP expression following TM pretreatment (35). As prior publications on IRI and HS/R have already demonstrated that an increased expression of $\mathrm{BiP}$ is accompanied by an upregulation of pPERK, IRE1, and ATF6 $(16,36,37)$ and as the focus of the present study was also on the topographical distribution of ER stress, we decided to only analyze BiP in whole liver homogenates. We chose $\mathrm{BiP}$ since it is a master regulator of $\mathrm{ER}$ function. As a member of the heat shock protein 70 family, BiP is a highly conserved molecular chaperone (8). However, it not only facilitates protein folding, but is also an essential component of quality control mechanisms of the secretory pathway and regulates endoluminal calcium concentration $(38,39)$. Additionally, and of the utmost importantance for the present study, $\mathrm{BiP}$ is a well-established marker of ER stress as its expression is induced by mal-/unfolded proteins $(40,41)$.
Interestingly, immunohistochemistry showed that BiP was not homogeneously increased but rather focused in the pericentral area. This topographic distribution pattern might be explained by the unique blood supply of the liver, which leads to a decreasing oxygen gradient from the periportal region towards the pericentral area (42). In several studies, Paxian et al $(43,44)$ demonstrated the resulting susceptibility to external stressors of pericentral hepatocytes, especially during hemorrhagic shock and the oxidant stress upon reperfusion. Consequently, these cells respond more sensitively to TM than periportal cells, indicated in the present study by the increased pericentral expression of ER stress marker BiP in both TM groups (44). Our finding of a topographic correlation of an upregulated $\mathrm{BiP}$ induction with the diminution of hepatocellular damage suggests that $\mathrm{BiP}$ has beneficial effects. This assumption is also supported by a recent publication from $\mathrm{Bi}$ et al (45), which demonstrated that an overexpression of BiP mitigated myocardial IRI. In line with the results of Paxian et al (43), the protective effect was mediated by inhibiting an accumulation of reactive oxygen species. Taking our observations and the current literature into account, we conclude that a pre-hemorrhagic BiP induction by TM administration mitigates post-hemorrhagic hepatocellular injury.

Whereas TM injection significantly altered BiP expression, its influence on the topographic patterns of ATF6 and IRE1 was limited. This difference might be based on the degradation of the proteins: The half-life of BiP is approximately $46 \mathrm{~h}$, while ATF6 and IRE1 are degraded with a half-life of about 2 and $3 \mathrm{~h}$, respectively (46-48). Consequently, the effect of TM on their topographic patterns might already have faded away $62 \mathrm{~h}$ after the injection. In contrast, PERK signaling, represented by pPERK, was markedly influenced by TM pretreatment. The homogeneous staining intensity in HS/R+TM group suggests an upregulation of the PERK pathway in the intermediary and pericentral zone. Even though PERK can contribute to cell death, we theorize that PERK signaling in the context of IRI and HS/R is primarily protective (49). The pro-survival effect might be mediated by the activation of the antioxidant response element via ATF4 and nuclear factor erythroid 
2-related factor 2 (Nrf2), resulting in an upregulation of protective enzymes (50). Since PERK activation thereby promotes beneficial effects, the increased pericentral expression of pPERK may explain the reduction of centrilobular cell death areas in the HS/R+TM group. Leung et al (51) recently demonstrated in a murine $\mathrm{HS} / \mathrm{R}$ model that Nrf2 plays a crucial role in the generation of protective factors induced by stress preconditioning and thus confirmed the importance of the PERK/ATF4/Nrf2 signaling branch.

In addition to its function as an activator of Nrf2, ATF4 is a key signal for ER stress induced autophagy (52). Although autophagy can play dual roles and may promote cell death, multiple studies attribute beneficial effects to the autophagic process during hypoperfusion or ischemia (53-55). Chandrika et al (53) demonstrated in the context of renal IRI that ER-stress induced autophagy provides cytoprotection. Yan et al (56) induced a subarachnoid hemorrhage in rats and described an autophagy dependent mitigation of early brain injury. Moreover, autophagy was shown to be hepatoprotective during a low-flow state, e.g. caused by septic shock (55). Previous studies reported that for correct autophagosome formation $\mathrm{BiP}$ is an obligatory component (57). Our immunohistochemical analysis supports this finding as the expression patterns of BiP and the autophagy marker Beclin1 were similar in the TM groups (33). Furthermore, our results underpin the hypothesis of Zhang et al (19), attributing a protective role to BiP dependent autophagy induction in the context of IRI. In the HS/R+TM group, Beclin1 expression was upregulated around the central vein, which indicates an increase in autophagic activity in the pericentral zone. With regard to the diminished liver damage in the HS/R+TM group, the topographic distribution of the cell death areas and Beclin1, the present study underlines the protective role of autophagy and identifies its activation as a beneficial mechanism.

Hepatic injury was analyzed by evaluating H\&E-stained liver tissue sections and measuring serum transaminases. We chose to use the umbrella term 'liver damage' because of the vague understanding of cell death mechanisms during $H S / R$. Although necrosis has been postulated as the predominant cell death mechanism, the occurrence of apoptosis and autophagy-related cell death has similarly been reported $(58,59)$. In the present work, we focused on ER stress as an underlying mechanism of the IRI as well as on the impact of ER stress preconditioning on organ damage. We did not investigate the exact modalities of ER stress associated cell death. In contrast to the long-standing assumption that prolonged ER stress only triggers apoptotic cell death, recent studies have demonstrated an ER stress induced caspase-independent cell death mechanism (60-62). Therefore, we suggest taking into account histomorphologic signs of both cell death modalities, when investigating post-hemorrhagic hepatocellular damage.

Interestingly, the results of the methods employed were not totally consistent. The discrepancy in the results of the two methods might be explained by the lengthy half-life of the liver transaminases on one hand and the liver's ability to regenerate on the other hand (63). Li et al (64) and Pajaud et al (65) determined the enormous regenerative potential of the murine liver as their data shows a completion of hepatocyte proliferation $72 \mathrm{~h}$ after two-thirds partial hepatectomy. The upregulation of early liver regeneration was particularly remarkable considering the debilitating, pre-hemorrhagic body weight loss of mice receiving TM. This body weight loss might be explained by the interplay of ER-stress and inflammation since it is known that ATF4 induces interleukin-6, which promotes adipose tissue lipolysis $(66,67)$. Therefore, ER-stress induction by TM may initiate an inflammatory response which, in turn, decreased body weight.

Since we focused on a fixed point in time, we can only speculate whether TM preconditioning lowered organ damage or if it merely accelerated liver regeneration. Previous studies focusing on IRI or partial hepatectomy $(\mathrm{PH})$ demonstrated the enormous potential of the liver to regenerate $(64,65,68)$. Furthermore, it has been shown that liver regeneration can be promoted through heat-shock proteins (HSPs) (69). As HSPs are upregulated through ER stress, we assume that TM preconditioning mediates its beneficial effects by accelerating liver regeneration via induction of HSPs, e.g. BiP $(8,70,71)$. However, to fully elucidate the temporal dynamics, a detailed time trial is needed. This trial should also include the analysis of transaminase and protein levels $48 \mathrm{~h}$ after TM injection. An upregulation of HSP expression just prior to hemorrhagic shock induction could support our above-mentioned assumption.

Since TM is not soluble in aqueous solution at $\mathrm{pH} 7.4$, the manufacturer recommends using DMSO as a solvent. Since DMSO increases serum transaminases, its influence should also be considered when evaluating the results of the histological and laboratory analysis as it could be another explanation for the aforementioned difference (72). However, the dosage applied in the present study was more than 100-fold below its median lethal dose, and in our previous studies we did not detect considerable differences comparing DV groups with mice undergoing sham or HS/R procedure without any drug injection $(18,73)$. Consequently, we assigned only three animals to each control group as we did not expect to augment scientific knowledge by including more mice and might thereby avoid raising ethical issues.

Furthermore, Beclin1 detection is no absolute criteria for determining autophagic status even though it is an established marker of autophagy onset $(33,74)$ Complementary to our analyses, it would be worth evaluating the expression of e.g. p62 or microtubule associated protein 1 light-chain 3 as these proteins are required for the formation of ubiquitinated protein aggregates and their delivery to the autophagy system (74). Detecting these proteins could confirm our conclusion and enable a deeper analysis of the pericentral autophagic processes. Nevertheless, looking at our data, there are further indicators of the induction of autophagy by TM preconditioning in addition to the increased Beclin1 expression. Furthermore, PERK activation was enhanced around the central vein in HS/R+TM group compared to all other groups. One target of the PERK pathway is ATF4, a key signal for autophagy induced by ER-stress (52). Regarding the concomitant upregulation of $\mathrm{BiP}$, which is an obligatory component of autophagy, these immunohistochemical findings support the assumption of a pericentral autophagy induction by TM preconditioning (57). Furthermore, we performed an immunohistochemical proof of CCAAT/Enhancer Binding Protein Homologous Protein (CHOP; data not shown), which is a target gene of ATF4 and has been shown to promote the transcription of several autophagy genes (49,75). In addition, an increased CHOP expression downregulates protein B-Cell Lymphoma 2 
(Bcl-2) (76). As Bcl-2 inhibits Beclin1-dependent autophagy, its downregulation facilitates autophagy induction (77). In the present study, the immunohistochemical analysis of liver tissue sections demonstrated an increased CHOP expression around the central vein in TM groups. As this finding suggests an upregulation of autophagy genes and a suppression of autophagy inhibition, it confirmed the above-mentioned results and supports the hypothesis of a pericentral autophagy induction by TM preconditioning. To further elucidate the importance of this finding, a selective post-hemorrhagic autophagy induction would be useful. Since TM influences $\mathrm{BiP}$ expression as well autophagy, this approach would help to differentiate the impact of these two mechanisms and highlight their clinical significance $(41,78)$.

A comparison of $\mathrm{BiP}$ western blot and immunohistochemistry reveals the strengths and weaknesses of both methods. Since the semi quantitative analysis of whole liver homogenates did not contain any information about the topographic distribution of $\mathrm{BiP}$, we also performed an immunohistochemical proof of BiP. Unexpectedly, the results of the two methods did not completely overlap. Our evaluation of the immunohistochemical staining suggested the highest BiP expression was in the $\mathrm{HS} / \mathrm{R}+\mathrm{DV}$ group. In contrast to this finding, the western blot analysis showed the highest BiP expression in the TM groups. The strong pericentral upregulation of $\mathrm{BiP}$ in $\mathrm{TM}$ groups may have outweighed the lower expression in the remaining zones, whereas in the $\mathrm{HS} / \mathrm{R}+\mathrm{DV}$ group the $\mathrm{BiP}$ expression in the vital liver parenchyma was not enough to compensate for the cell death areas. To backup this assumption, for the future we propose microdissecting the individual liver zones followed by western blot or PCR analyses. This approach makes possible the detection of topographical changes and their simultaneous quantification.

In the present study, we confirmed previous results reporting a significant role for the UPR in IRI. In addition, we demonstrated that the injection of the ER stress inducer tunicamycin mitigates post-hemorrhagic hepatocellular injury. By analyzing topographic expression patterns, we identified an upregulated $\mathrm{BiP}$ expression and a concomitant autophagy induction as potential beneficial mechanisms. In conclusion, ER stress preconditioning alleviates post-hemorrhagic liver damage and may lead to novel therapeutic targets.

\section{Acknowledgements}

The authors would like to thank Prof.Dr. Gerhard Schmidmaier (Department of Trauma Surgery, University of Heidelberg, Heidelberg) for his valuable support and are grateful for the skillful technical assistance of Ms Birgit Frey (Department of Trauma Surgery, University of Heidelberg, Germany).

\section{Funding}

This research was funded by the University of Heidelberg, Germany.

\section{Availability of data and materials}

The datasets used and/or analyzed during the current study are available from the corresponding author on reasonable request.

\section{Authors' contributions}

The conception and design of the study was performed by DPO and SK, the acquisition of data was carried out by DPO and AKW. DPO, AKW, NLG and SK analyzed and interpreted the data. DPO drafted the article and all authors revised it critically for important intellectual content. All authors approved the final version to be submitted.

\section{Ethics approval and consent to participate}

All study protocols were reviewed and approved by the section for agriculture and veterinary services of the Regional Council, Karlsruhe, Germany (35-9185.81/ G-65/13).

\section{Patient consent for publication}

Not applicable.

\section{Competing interests}

The authors declare that they have no competing interests.

\section{References}

1. Heron M: Deaths: Leading Causes for 2012. Natl Vital Stat Rep 64: 1-94, 2015.

2. GBD 2016 Causes of Death Collaborators: Global, regional, and national age-sex specific mortality for 264 causes of death, 1980-2016: A systematic analysis for the global burden of disease study 2016. Lancet 390: 1151-1210, 2017.

3. Rhee P, Joseph B, Pandit V, Aziz H, Vercruysse G, Kulvatunyou N and Friese RS: Increasing trauma deaths in the United States. Ann Surg 260: 13-21, 2014.

4. Eastridge BJ, Holcomb JB and Shackelford S: Outcomes of traumatic hemorrhagic shock and the epidemiology of preventable death from injury. Transfusion 59: 1423-1428, 2019.

5. Kauvar DS, Lefering R and Wade CE: Impact of hemorrhage on trauma outcome: An overview of epidemiology, clinical presentations, and therapeutic considerations. J Trauma 60 (Suppl 6): S3-S11, 2006.

6. Sciandra JJ, Subjeck JR and Hughes CS: Induction of glucose-regulated proteins during anaerobic exposure and of heat-shock proteins after reoxygenation. Proc Natl Acad Sci USA 81: 4843-4847, 1984.

7. Hetz C, Chevet E and Oakes SA: Proteostasis control by the unfolded protein response. Nat Cell Biol 17: 829-838, 2015.

8. Wang J, Lee J, Liem D and Ping P: HSPA5 gene encoding Hsp70 chaperone $\mathrm{BiP}$ in the endoplasmic reticulum. Gene 618: 14-23, 2017.

9. Bertolotti A, Zhang Y, Hendershot LM, Harding HP and Ron D: Dynamic interaction of $\mathrm{BiP}$ and ER stress transducers in the unfolded-protein response. Nat Cell Biol 2: 326-332, 2000.

10. Ye J, Rawson RB, Komuro R, Chen X, Davé UP, Prywes R, Brown MS and Goldstein JL: ER stress induces cleavage of membrane-bound ATF6 by the same proteases that process SREBPs. Mol Cell 6: 1355-1364, 2000.

11. Yoshida H, Okada T, Haze K, Yanagi H, Yura T, Negishi M and Mori K: ATF6 activated by proteolysis binds in the presence of NF-Y (CBF) directly to the cis-acting element responsible for the mammalian unfolded protein response. Mol Cell Biol 20: 6755-6767, 2000.

12. Yoshida H, Matsui T, Yamamoto A, Okada T and Mori K: XBP1 mRNA is induced by ATF6 and spliced by IRE1 in response to ER stress to produce a highly active transcription factor. Cell 107: 881-891, 2001.

13. Yoshida H, Matsui T, Hosokawa N, Kaufman RJ, Nagata K and Mori K: A time-dependent phase shift in the mammalian unfolded protein response. Dev Cell 4: 265-271, 2003. 
14. Harding HP, Zhang Y and Ron D: Protein translation and folding are coupled by an endoplasmic-reticulum-resident kinase. Nature 397: 271-274, 1999.

15. Zinszner H, Kuroda M, Wang X, Batchvarova N, Lightfoot RT, Remotti H, Stevens JL and Ron D: CHOP is implicated in programmed cell death in response to impaired function of the endoplasmic reticulum. Genes Dev 12: 982-995, 1998

16. Jian B, Hsieh CH, Chen J, Choudhry M, Bland K, Chaudry I and Raju R: Activation of endoplasmic reticulum stress response following trauma-hemorrhage. Biochim Biophys Acta 1782: 621-626, 2008

17. Wolpert A, Obert D, Frey B, Lee YS and Korff S: Hepatic topographical changes of endoplasmic reticulum stress and unfolded protein response signaling after hemorrhagic shock and reperfusion. J Surg Res 231: 278-289, 2018

18. Obert DP, Wolpert AK and Korff S: Modulation of endoplasmic reticulum stress influences ischemia-reperfusion injury after hemorrhagic shock. Shock 52: e76-e84, 2019.

19. Zhang XY, Zhang TT, Song DD, Zhou JH, Han R, Qin ZH and Sheng R: Endoplasmic reticulum chaperone GRP78 is involved in autophagy activation induced by ischemic preconditioning in neural cells. Mol Brain 8: 20, 2015.

20. Li J, Lai X, Chen Y, Niu B and Gong J: Endotoxin tolerance attenuates liver ischemia/reperfusion injury by down-regulation of interleukin-1 receptor-associated kinase 4 in kupffer cells. Transplant Proc 43: 2531-2535, 2011

21. Thielmann M, Kottenberg E, Kleinbongard P, Wendt D, Gedik N, Pasa S, Price V, Tsagakis K, Neuhäuser M, Peters J, et al: Cardioprotective and prognostic effects of remote ischaemic preconditioning in patients undergoing coronary artery bypass surgery: A single-centre randomised, double-blind, controlled trial. Lancet 382: 597-604, 2013.

22. Birnbaum Y, Hale SL and Kloner RA: Ischemic preconditioning at a distance: Reduction of myocardial infarct size by partia reduction of blood supply combined with rapid stimulation of the gastrocnemius muscle in the rabbit. Circulation 96: 1641-1646, 1997.

23. Hildebrand F, Hubbard WJ, Choudhry MA, Frink M, Pape HC, Kunkel SL and Chaudry IH: Kupffer cells and their mediators: The culprits in producing distant organ damage after trauma-hemorrhage. Am J Pathol 169: 784-794, 2006.

24. Wallig MA, Haschek WM, Rousseaux CG, Bolon B and Mahler BW: Fundamentals of toxicologic pathology. Elsevier/Academic Press, London, 2018.

25. Matsuo A, Watanabe A, Takahashi T, Futamura M, Mori S, Sugiyama Y, Takahashi Y and Saji S: A simple method for classification of cell death by use of thin layer collagen gel for the detection of apoptosis and/or necrosis after cancer chemotherapy. Jpn J Cancer Res 92: 813-819, 2001.

26. Hentschke $\mathrm{H}$ and Stuttgen MC: Computation of measures of effect size for neuroscience data sets. Eur J Neurosci 34 1887-1894, 2011

27. Amrhein V, Greenland S and McShane B: Scientists rise up against statistical significance. Nature 567: 305-307, 2019.

28. Pfeifer R, Lichte P, Schreiber H, Sellei RM, Dienstknecht T, Sadeghi C, Pape HC and Kobbe P: Models of hemorrhagic shock: Differences in the physiological and inflammatory response. Cytokine 61: 585-590, 2013.

29. James O, Lesna M, Roberts SH, Pulman L, Douglas AP, Smith PA and Watson AJ: Liver damage after paracetamol overdose. Comparison of liver-function tests, fasting serum bile acids, and liver histology. Lancet 2: 579-581, 1975

30. Oslowski CM and Urano F: Measuring ER stress and the unfolded protein response using mammalian tissue culture system. Methods Enzymol 490: 71-92, 2011.

31. Haze K, Yoshida H, Yanagi H, Yura T and Mori K: Mammalian transcription factor ATF6 is synthesized as a transmembrane protein and activated by proteolysis in response to endoplasmic reticulum stress. Mol Biol Cell 10: 3787-3799, 1999.

32. Shen J, Chen X, Hendershot L and Prywes R: ER stress regulation of ATF6 localization by dissociation of BiP/GRP78 binding and unmasking of Golgi localization signals. Dev Cell 3: 99-111, 2002.

33. Liang XH, Jackson S, Seaman M, Brown K, Kempkes B, Hibshoosh $\mathrm{H}$ and Levine B: Induction of autophagy and inhibition of tumorigenesis by beclin 1. Nature 402: 672-676, 1999.

34. Tkacz JS and Lampen O: Tunicamycin inhibition of polyisoprenyl $\mathrm{N}$-acetylglucosaminyl pyrophosphate formation in calf-liver microsomes. Biochem Biophys Res Commun 65: 248-257, 1975.
35. Prachasilchai W, Sonoda H, Yokota-Ikeda N, Oshikawa S, Aikawa C, Uchida K, Ito K, Kudo T, Imaizumi K and Ikeda M: A protective role of unfolded protein response in mouse ischemic acute kidney injury. Eur J Pharmacol 592: 138-145, 2008.

36. Thacker SA, Robinson P, Abel A and Tweardy DJ: Modulation of the unfolded protein response during hepatocyte and cardiomyocyte apoptosis in trauma/hemorrhagic shock. Sci Rep 3: 1187 , 2013.

37. Duvigneau JC, Kozlov AV, Zifko C, Postl A, Hartl RT, Miller I, Gille L, Staniek K, Moldzio R, Gregor W, et al: Reperfusion does not induce oxidative stress but sustained endoplasmic reticulum stress in livers of rats subjected to traumatic-hemorrhagic shock. Shock 33: 289-298, 2010.

38. Ellgaard L and Helenius A: Quality control in the endoplasmic reticulum. Nat Rev Mol Cell Biol 4: 181-191, 2003

39. Schauble N, Lang S, Jung M, Cappel S, Schorr S, Ulucan O, Linxweiler J, Dudek J, Blum R, Helms V, et al: BiP-mediated closing of the Sec61 channel limits $\mathrm{Ca}^{2+}$ leakage from the ER. EMBO J 31: 3282-3296, 2012.

40. Lee AS: The ER chaperone and signaling regulator GRP78/BiP as a monitor of endoplasmic reticulum stress. Methods 35: 373-381, 2005.

41. Kozutsumi Y, Segal M, Normington K, Gething MJ and Sambrook J: The presence of malfolded proteins in the endoplasmic reticulum signals the induction of glucose-regulated proteins. Nature 332: 462-464, 1988

42. Paxian M, Keller SA, Cross B, Huynh TT and Clemens MG: High-resolution visualization of oxygen distribution in the liver in vivo. Am J Physiol Gastrointest Liver Physiol 286: G37-G44, 2004.

43. Paxian M, Bauer I, Kaplan D, Bauer M and Rensing H: Hepatic redox regulation of transcription factors activator protein-1 and nuclear factor-kappaB after hemorrhagic shock in vivo. Antioxid Redox Signal 4: 711-720, 2002.

44. Paxian M, Bauer I, Rensing H, Jaeschke H, Mautes AEM, Kolb SA, Wolf B, Stockhausen A, Jeblick S and Bauer M: Recovery of hepatocellular ATP and 'pericentral apoptosis' after hemorrhage and resuscitation. FASEB J 17: 993-1002, 2003.

45. Bi X,Zhang G, Wang X, Nguyen C, May HI,Li X, Al-Hashimi AA, Austin RC, Gillette TG, Fu G, et al: Endoplasmic reticulum chaperone GRP78 protects heart from ischemia/reperfusion injury through akt activation. Circ Res 122: 1545-1554, 2018.

46. Rutkowski DT, Arnold SM, Miller CN, Wu J, Li J, Gunnison KM, Mori K, Akha AAS, Raden D and Kaufman RJ: Adaptation to ER stress is mediated by differential stabilities of pro-survival and pro-apoptotic mRNAs and proteins. PLoS Biol 4: e374, 2006.

47. Gao B, Lee SM, Chen A, Zhang J, Zhang DD, Kannan K, Ortmann RA and Fang D: Synoviolin promotes IRE1 ubiquitination and degradation in synovial fibroblasts from mice with collagen-induced arthritis. EMBO Rep 9: 480-485, 2008.

48. Sato Y, Nadanaka S, Okada T, Okawa K and Mori K: Luminal domain of ATF6 alone is sufficient for sensing endoplasmic reticulum stress and subsequent transport to the Golgi apparatus. Cell Struct Funct 36: 35-47, 2011.

49. Fawcett TW, Martindale JL, Guyton KZ, Hai T and Holbrook NJ: Complexes containing activating transcription factor (ATF)/cAMP-responsive-element-binding protein (CREB) interact with the CCAAT/enhancer-binding protein (C/EBP)-ATF composite site to regulate Gadd153 expression during the stress response. Biochem J 339: 135-141, 1999.

50. He CH, Gong P, Hu B, Stewart D, Choi ME, Choi AM and Alam J: Identification of activating transcription factor 4 (ATF4) as an Nrf2-interacting protein. Implication for heme oxygenase-1 gene regulation. J Biol Chem 276: 20858-20865, 2001.

51. Leung $\mathrm{CH}$, Caldarone CA, Guan R, Wen XY, Ailenberg M, Kapus A, Szaszi K and Rotstein OD: Nrf2 regulates the hepatoprotective effects of remote ischemic conditioning in hemorrhagic shock. Antioxid Redox Signal 30: 1760-1773, 2019.

52. Matsumoto H, Miyazaki S, Matsuyama S, Takeda M, Kawano M, Nakagawa H, Nishimura K and Matsuo S: Selection of autophagy or apoptosis in cells exposed to ER-stress depends on ATF4 expression pattern with or without CHOP expression. Biol Open 2: 1084-1090, 2013.

53. Chandrika BB, Yang C, Ou Y, Feng X, Muhoza D, Holmes AF, Theus S, Deshmukh S, Haun RS and Kaushal GP: Endoplasmic reticulum stress-induced autophagy provides cytoprotection from chemical hypoxia and oxidant injury and ameliorates renal ischemia-reperfusion injury. PLoS One 10: e0140025, 2015. 
54. Hsieh YC, Athar M and Chaudry IH: When apoptosis meets autophagy: Deciding cell fate after trauma and sepsis. Trends Mol Med 15: 129-138, 2009.

55. Oami T, Watanabe E, Hatano M, Teratake Y, Fujimura L, Sakamoto A, Ito C, Toshimori K, Swanson PE and Oda S: Blocking liver autophagy accelerates apoptosis and mitochondrial injury in hepatocytes and reduces time to mortality in a murine sepsis model. Shock 50: 427-434, 2018.

56. Yan F, Li J, Chen J, Hu Q, Gu C, Lin W and Chen G: Endoplasmic reticulum stress is associated with neuroprotection against apoptosis via autophagy activation in a rat model of subarachnoid hemorrhage. Neurosci Lett 563: 160-165, 2014.

57. Li J, Ni M, Lee B, Barron E, Hinton DR and Lee AS: The unfolded protein response regulator GRP78/BiP is required for endoplasmic reticulum integrity and stress-induced autophagy in mammalian cells. Cell Death Differ 15: 1460-1471, 2008.

58. Cursio R, Colosetti P and Gugenheim J: Autophagy and liver ischemia-reperfusion injury. Biomed Res Int 2015: 417590, 2015.

59. Cursio R, Colosetti P, Saint-Paul MC, Pagnotta S, Gounon P, Iannelli A, Auberger P and Gugenheim J: Induction of different types of cell death after normothermic liver ischemia-reperfusion. Transplant Proc 42: 3977-3980, 2010.

60. Sovolyova N, Healy S, Samali A and Logue SE: Stressed to death-mechanisms of ER stress-induced cell death. Biol Chem 395: 1-13, 2014.

61. Saveljeva S, Mc Laughlin SL, Vandenabeele P, Samali A and Bertrand MJ: Endoplasmic reticulum stress induces ligandindependent TNFR1-mediated necroptosis in L929 cells. Cell Death Dis 6: e1587, 2015.

62. Santofimia-Castano P, Lan W, Bintz J, Gayet O, Carrier A, Lomberk G, Neira JL, González A, Urrutia R, Soubeyran P and Iovanna J: Inactivation of NUPR1 promotes cell death by coupling ER-stress responses with necrosis. Sci Rep 8: 16999, 2018.

63. Kim WR, Flamm SL, Di Bisceglie AM, Bodenheimer HC and Public Policy Committee of the American Association for the Study of Liver Disease: Serum activity of alanine aminotransferase (ALT) as an indicator of health and disease. Hepatology 47: 1363-1370, 2008.

64. Li D, Li J, Wang G, Qin Y, Niu Z, Li Z and Xu C: Delayed liver regeneration after partial hepatectomy in aged Nos2 knockout mice. Cell J 19: 218-230, 2017.

65. Pajaud J, Ribault C, Ben Mosbah I, Rauch C, Henderson C, Bellaud P, Aninat C, Loyer P, Morel F and Corlu A: Glutathione transferases $\mathrm{P} 1 / \mathrm{P} 2$ regulate the timing of signaling pathway activations and cell cycle progression during mouse liver regeneration. Cell Death Dis 6: e1598, 2015.

66. Han J, Meng Q, Shen L and Wu G: Interleukin-6 induces fat loss in cancer cachexia by promoting white adipose tissue lipolysis and browning. Lipids Health Dis 17: 14, 2018.
67. Iwasaki Y, Suganami T, Hachiya R, Shirakawa I, Kim-Saijo M, Tanaka M, Hamaguchi M, Takai-Igarashi T, Nakai M, Miyamoto $\mathrm{Y}$ and Ogawa $\mathrm{Y}$ : Activating transcription factor 4 links metabolic stress to interleukin-6 expression in macrophages. Diabetes 63: 152-161, 2014.

68. Karatzas T, Neri AA, Baibaki ME and Dontas IA: Rodent models of hepatic ischemia-reperfusion injury: Time and percentage-related pathophysiological mechanisms. J Surg Res 191: 399-412, 2014.

69. Oka Y, Akagi Y, Kinugasa T, Ishibashi N, Iwakuma N, Shiratsuchi I and Shirouzu K: Heat-shock pre-treatment reduces liver injury and aids liver recovery after partial hepatectomy in mice. Anticancer Res 33: 2887-2894, 2013.

70. Chien CY, Chien CT and Wang SS: Progressive thermopreconditioning attenuates rat cardiac ischemia/reperfusion injury by mitochondria-mediated antioxidant and antiapoptotic mechanisms. J Thorac Cardiovasc Surg 148: 705-713, 2014.

71. Liu Y and Chang A: Heat shock response relieves ER stress. EMBO J 27: 1049-1059, 2008.

72. Pestel S, Martin HJ, Maier GM and Guth B: Effect of commonly used vehicles on gastrointestinal, renal, and liver function in rats. J Pharmacol Toxicol Methods 54: 200-214, 2006.

73. Willson JE, Brown DE and Timmens EK: A toxicologic study of dimethyl sulfoxide. Toxicol Appl Pharmacol 7: 104-112, 1965.

74. Klionsky DJ, Abdalla FC, Abeliovich H, Abraham RT, Acevedo-Arozena A, Adeli K, Agholme L, Agnello M, Agostinis P, Aguirre-Ghiso JA, et al: Guidelines for the use and interpretation of assays for monitoring autophagy. Autophagy 8: 445-544, 2012.

75. B'Chir W, Chaveroux C, Carraro V, Averous J, Maurin AC Jousse C, Muranishi Y, Parry L, Fafournoux P and Bruhat A: Dual role for CHOP in the crosstalk between autophagy and apoptosis to determine cell fate in response to amino acid deprivation. Cell Signal 26: 1385-1391, 2014.

76. McCullough KD, Martindale JL, Klotz LO, Aw TY and Holbrook NJ: Gadd153 sensitizes cells to endoplasmic reticulum stress by down-regulating $\mathrm{Bcl} 2$ and perturbing the cellular redox state. Mol Cell Biol 21: 1249-1259, 2001.

77. Pattingre S, Tassa A, Qu X, Garuti R, Liang XH, Mizushima N, Packer M, Schneider MD and Levine B: Bcl-2 antiapoptotic proteins inhibit Beclin 1-dependent autophagy. Cell 122: 927-939, 2005.

78. Yorimitsu T, Nair U, Yang Z and Klionsky DJ: Endoplasmic reticulum stress triggers autophagy. J Biol Chem 281: 30299-30304, 2006.

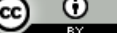

This work is licensed under a Creative Commons Attribution 4.0 International (CC BY 4.0) License. 